\section{The Impact of Surgery Resident Participation on the Outcome of Carotid Endarterectomy}

Alex D. Ammar, M.D.

University of Kansas School of Medicine-Wichita, Department of Surgery

Received April 10, 2019; Accepted for publication Aug. 14, 2019; Published online.Jan. 31, 2020

\begin{abstract}
Introduction. The purpose of this study was to determine whether the in-hospital stroke rate plus deaths (SD) was adversely impacted by the participation of surgery residents during carotid endarterectomy.
\end{abstract}

Methods. A single board-certified vascular surgeon performed 5,663 carotid endarterectomies (CEAs) from September 1982 through December 2016. The surgeon prospectively recorded the data used in this report during the patient's hospital stay. These cases were done at five hospitals, three of which had general surgery residents participating in procedures and two that did not.

Results. Of the 5,663 CEAs, residents participated at three hospitals in 4,974 CEAs. In the two hospitals that did not have surgery residents participating, 689 CEAs were performed. Fifty-seven strokes and 12 deaths occurred in hospitals with resident participation (SD 1.39\%). Six strokes (0.9\%) and no deaths occurred in hospitals without resident participation. No significant difference in stroke rate, death rate, or combined stroke plus death rate (SD) were identified in comparing hospitals with or without resident participation.

Conclusion. This report corroborates others that senior general surgery residents did not have a significant impact on SD in patients undergoing CEA. Kans J Med 2020;13:6-8.

\section{INTRODUCTION}

Carotid endarterectomy (CEA) is a commonly performed vascular surgical procedure and is an important treatment modality in stroke prevention. It is technically demanding, requiring meticulous attention to detail to reduce perioperative stroke morbidity and mortality. Further, the surgery Residency Review Committee (RRC) of the Accreditation Council for Graduate Medical Education (ACGME) requires rotations in vascular surgery for general surgery residents. The impact of the participation of surgery residents on stroke morbidity and mortality during CEA has been addressed previously. ${ }^{1-11}$ Nonetheless, these studies were not prospective, were not over the entire career of a single vascular surgeon, and did not evaluate a single surgeon's experience performing CEA both with and without residents during the same time span.

The purpose of this study was to determine whether the in-hospital stroke rate and deaths (SD) were impacted adversely by the participation of surgery residents during operation.

\section{METHODS}

Patient Population. A single board-certified vascular surgeon (ADA) performed 5,663 CEAs from September 1982 through December 2016. These operations included 246 redo CEAs. Patients
KANSAS JOURNAL of MEDIC INE

undergoing concomitant CEA with another procedure, such as coronary artery bypass, were excluded. All data collected for this study came from records of the author's private practice, which is not a covered entity, and as such did not require institutional review board approval or patient informed consent. The data was hand-written into a casebook by the author. The author prospectively recorded the following information during the patient's hospital stay: name of patient, demographic data (age and sex), comorbidities, date of operation, hospital where performed, diagnosis, symptom status, procedure performed, and in-hospital complications including stroke and death.

Hospital Characteristics and Operative Procedure. The preoperative work-up, indications for surgery, technical aspects of performing CEA, perioperative care including preoperative and postoperative standing orders, and postoperative follow-up were similar at each of the five participating hospitals and have been reported previously. ${ }^{12-16}$ The majority of operations were performed at two large, tertiary-care, community-based hospitals, as well as the Veterans Administration Medical Center (VA) in Wichita, Kansas, all affiliated with the University of Kansas School of Medicine-Wichita. The author was present for the entirety of every CEA with the exception of skin closure. When a senior (4th or 5th year) surgery resident was present in the operating room, the author assisted the senior resident in performing the majority of the operation depending on the resident's technical skills, as well as the complexity of the case. Although not specifically recorded, the author estimated that he performed the majority of the CEA in less than $10 \%$ of cases when a senior resident was present for the case, either because of difficult anatomy (such as high bifurcation, re-operations, or distal plaque) or junior resident first assist. Our surgery residency program trains six residents per year. There are no vascular fellows. At two hospitals, surgery residents did not participate.

All patients suspected of having clinical stroke (i.e., aphasia, contralateral hemiparesis, visual disturbances) while in the hospital had confirmatory computerized tomography or magnetic resonance imaging at all sites. These patients with clinical symptoms and physical findings plus a positive scan were considered to have a stroke.

Statistical Analysis. The author reviewed and tabulated all data manually. Data were complete for all patients. Data were stratified according to resident involvement. Hospitals A, B, and C were resident teaching hospitals and residents participated in CEA operations at these hospitals. Hospitals D and $\mathrm{E}$ were not resident teaching hospitals. Qualitative data were analyzed with Chi-Square analysis. All analyses were conducted as 2-tailed tests and the alpha value for statistical significance was set at $\mathrm{p} \leq 0.05$. All analyses were conducted using SPSS 19.0 (IBM Corp., Somers, New York). 
KANSAS JOURNAL of MEDICINE

IMPACT OF SURGERY RESIDENTS ON CEA

OUTCOMES

continued.

\section{RESULTS}

From 1982 through 2016, a total of 5,663 CEAs were performed at five hospitals in Wichita, Kansas. Demographic data are tabulated in Table 1. Demographics were comparable between the hospitals with and without resident involvement, although the hospitals with resident involvement treated more patients with hypertension, diabetes mellitus, and hyperlipidemia. The symptomatic status of patients was similar at both hospitals. The number of cases covered by surgery residents in the three resident hospitals with resident involvement was $1,763,3,190$, and 21 , respectively (Table 2 ). In the two hospitals without resident involvement, 246 and 443 CEAs, respectively, were performed. Deaths from ischemic stroke were counted only under deaths and not both stroke and death so that each patient was counted only once.

Table 1. Patient demographics and comorbidities.

\begin{tabular}{|l|c|c|c|}
\hline Parameter & $\begin{array}{c}\text { Hospitals } \\
\text { with Resident } \\
\text { Involvement } \\
\text { (n= 3) } \\
\text { Number (\%) }\end{array}$ & $\begin{array}{c}\text { Hospitals without } \\
\text { Resident } \\
\text { Involvement } \\
\text { (n= 2) } \\
\text { Number (\%) }\end{array}$ & $\begin{array}{c}\text { p } \\
\text { value }\end{array}$ \\
\hline Number of observations & $4,974(87.8)$ & $689(12.2)$ & --- \\
\hline Age, years (mean) & 73.9 & 78.2 & \\
\hline Male sex & $2,726(54.8)$ & $365(53.0)$ & 0.366 \\
\hline Hypertension & $4,158(83.6)$ & $544(79.0)$ & 0.002 \\
\hline Dyslipidemia & $3,482(70.0)$ & $455(66.0)$ & 0.034 \\
\hline $\begin{array}{l}\text { Smoking (current or } \\
\text { previous) }\end{array}$ & $2,970(59.7)$ & $396(57.5)$ & 0.263 \\
\hline Symptomatic & $2,830(56.9)$ & $384(55.7)$ & 0.564 \\
\hline Heart disease & $2,641(53.1)$ & $359(52.1)$ & 0.625 \\
\hline Diabetes mellitus & $1,442(29.0)$ & $168(24.4)$ & 0.012 \\
\hline Congestive heart failure & $294(5.9)$ & $38(5.5)$ & 0.679 \\
\hline End-stage renal disease & $112(2.3)$ & $15(2.2)$ & 0.901 \\
\hline
\end{tabular}

In-hospital stroke and death rates at the various hospitals are outlined in Table 2. When comparing all five hospitals studied, the rate of stroke (ischemic and hemorrhagic) and death (from ischemic stroke, hemorrhagic stroke, and myocardial infarction) were similar between the five hospitals. The combined stroke plus death rates (SD) were not significantly different between hospitals: hospital $\mathrm{A}=1.7 \%, \mathrm{~B}$

$=1.1 \%, \mathrm{C}=0 . \%, \mathrm{D}=0.8 \%, \mathrm{E}=0.9 \%(\mathrm{p}=0.361)$. In comparing the outcomes in hospitals with resident involvement to those without, the combined stroke plus death rates were similar (Table 3). Residents participated in the care of 4,974 patients resulting in 57 strokes $(1.15 \%)$ and 12 deaths $(0.24 \%$; $\mathrm{SD}=1.39 \%)$. This compared with the 689 patients cared for without resident involvement resulting in 6 strokes $(0.9 \%)$ and no deaths $(\mathrm{SD}=0.9 \%)$. The average hospital length of hospital stay during the author's career decreased from 2.5 days to 1.4 days.
Table 2. Comparison of stroke and death rate by hospital.

\begin{tabular}{|c|c|c|c|c|c|c|}
\hline \multirow{2}{*}{ Parameter } & \multicolumn{3}{|c|}{$\begin{array}{l}\text { Hospitals with Resident } \\
\text { Involvement }\end{array}$} & \multicolumn{2}{|c|}{$\begin{array}{c}\text { Hospitals without } \\
\text { Resident } \\
\text { Involvement }\end{array}$} & \multirow{2}{*}{$\begin{array}{c}\mathbf{p} \\
\text { value }\end{array}$} \\
\hline & $\begin{array}{c}\text { Hospital } \\
\text { A }\end{array}$ & $\begin{array}{c}\text { Hospital } \\
\text { B }\end{array}$ & $\underset{\text { C }}{\text { Hospital }}$ & $\begin{array}{c}\text { Hospital } \\
\text { D }\end{array}$ & $\underset{\mathrm{E}}{\text { Hospital }}$ & \\
\hline Observations & $\begin{array}{c}1,763 \\
(31.1 \%)\end{array}$ & $\begin{array}{c}3,190 \\
(56.3 \%)\end{array}$ & $\begin{array}{c}21 \\
(0.4 \%)\end{array}$ & $\begin{array}{c}246 \\
(4.3 \%)\end{array}$ & $\begin{array}{c}443 \\
(7.8 \%)\end{array}$ & --- \\
\hline $\begin{array}{l}\text { Ischemic } \\
\text { stroke }\end{array}$ & $\begin{array}{c}25 \\
(1.42 \%)\end{array}$ & $\begin{array}{c}29 \\
(0.91 \%)\end{array}$ & $\begin{array}{c}0 \\
(0.0 \%)\end{array}$ & $\begin{array}{c}2 \\
(0.81 \%)\end{array}$ & $4(0.9 \%)$ & 0.506 \\
\hline $\begin{array}{l}\text { Hemorrhagic } \\
\text { stroke }\end{array}$ & $\begin{array}{c}1 \\
(0.06 \%)\end{array}$ & $\begin{array}{c}2 \\
(0.06 \%)\end{array}$ & $\begin{array}{c}0 \\
(0.0 \%)\end{array}$ & $\begin{array}{c}0 \\
(0.0 \%)\end{array}$ & $\begin{array}{c}0 \\
(0.0 \%)\end{array}$ & 0.979 \\
\hline All strokes & $\begin{array}{c}26 \\
(1.47 \%)\end{array}$ & $\begin{array}{c}31 \\
(0.97 \%)\end{array}$ & $\begin{array}{c}0 \\
(0.0 \%)\end{array}$ & $\begin{array}{c}2 \\
(0.81 \%)\end{array}$ & $\begin{array}{c}4 \\
(0.9 \%)\end{array}$ & 0.510 \\
\hline \multicolumn{7}{|l|}{ Death from: } \\
\hline $\begin{array}{l}\text { Ischemic } \\
\text { stroke }\end{array}$ & $\begin{array}{c}2 \\
(0.11 \%)\end{array}$ & $\begin{array}{c}2 \\
(0.6 \%)\end{array}$ & $\begin{array}{c}0 \\
(0.0 \%)\end{array}$ & $\begin{array}{c}0 \\
(0.0 \%)\end{array}$ & $\begin{array}{c}0 \\
(0.0 \%)\end{array}$ & 0.912 \\
\hline $\begin{array}{l}\text { Hemorrhagic } \\
\text { stroke }\end{array}$ & $\begin{array}{c}0 \\
(0.0 \%)\end{array}$ & $\begin{array}{c}0 \\
(0.0 \%)\end{array}$ & $\begin{array}{c}0 \\
(0.0 \%)\end{array}$ & $\begin{array}{c}0 \\
(0.0 \%)\end{array}$ & $\begin{array}{c}0 \\
(0.0 \%)\end{array}$ & --- \\
\hline $\begin{array}{l}\text { Myocardial } \\
\text { infarction }\end{array}$ & $\begin{array}{c}3 \\
(0.17 \%)\end{array}$ & $\begin{array}{c}5 \\
(0.16 \%)\end{array}$ & $\begin{array}{c}0 \\
(0.0 \%)\end{array}$ & $\begin{array}{c}0 \\
(0.0 \%)\end{array}$ & $\begin{array}{c}0 \\
(0.0 \%)\end{array}$ & 0.884 \\
\hline All Deaths & $\begin{array}{c}5 \\
(0.28 \%)\end{array}$ & $\begin{array}{c}7 \\
(0.22 \%)\end{array}$ & $\begin{array}{c}0 \\
(0.0 \%)\end{array}$ & $\begin{array}{c}0 \\
(0.0 \%)\end{array}$ & $\begin{array}{c}0 \\
(0.0 \%)\end{array}$ & 0.746 \\
\hline $\begin{array}{l}\text { Stroke + } \\
\text { Death }\end{array}$ & $\begin{array}{c}31 \\
(1.76 \%)\end{array}$ & $\begin{array}{c}38 \\
(1.19 \%)\end{array}$ & $\begin{array}{c}0 \\
(0.0 \%)\end{array}$ & $\begin{array}{c}2 \\
(0.81 \%)\end{array}$ & $\begin{array}{c}4 \\
(0.9 \%)\end{array}$ & 0.361 \\
\hline
\end{tabular}

Table 3. Comparison of stroke and death rate for resident and non-resident hospitals.

\begin{tabular}{|l|c|c|c|}
\hline Parameter & $\begin{array}{c}\text { Hospitals } \\
\text { with Resident } \\
\text { Involvement } \\
\text { (n= 3) } \\
\text { Number (\%) }\end{array}$ & $\begin{array}{c}\text { Hospitals without } \\
\text { Resident } \\
\text { Involvement } \\
\text { (n= 2) } \\
\text { Number (\%) }\end{array}$ & p value \\
\hline $\begin{array}{l}\text { Number of } \\
\text { observations }\end{array}$ & $4,974(87.8)$ & $689(12.2)$ & -- \\
\hline Stroke & $57(1.1 .5)$ & $6(0.9)$ & 0.519 \\
\hline Death & $12(0.24)$ & $0(0.0)$ & 0.197 \\
\hline Stroke + Death & $69(1.39)$ & $6(0.9)$ & 0.266 \\
\hline
\end{tabular}

\section{DISCUSSION}

The training of general surgery residents is an important professional responsibility of attending surgeons. Knowledge of vascular surgery is a core component of the general surgical residency curriculum. Training programs must offer rotations in vascular surgery to meet requirements of the surgery RRC and the ACGME. Carotid endarterectomy is ideal for teaching the basics of the technical aspects of vascular surgery if patient safety is not sacrificed. Nonetheless, patients are at risk of stroke if the procedure is done carelessly.

Over the past three decades, medical management of carotid disease has improved with newer antiplatelet agents, statins and newer blood pressure medications. These medical advances should benefit patients similarly at all hospitals studied. Nevertheless, CEA was performed at five hospitals, three affiliated with the University of Kansas School of Medicine-Wichita, thus having resident involvement, and two without resident involvement. The author was afforded the opportunity to assess the impact of surgery resident participation in performing CEA. In-hospital stroke and mortality rates were similar at all five institutions, although the stroke rate appeared 
slightly higher, but not statistically significant, at hospital A. Therefore, it is reasonable to conclude that with adequate supervision, senior general surgery residents can participate in CEA without increasing SD. Our results corroborated several other reports that were not prospective, had fewer cases or completed by multiple surgeons, and were not conducted by assessing the results with and without residents during the same period of time. ${ }^{1-11}$ This information should be helpful in supporting the involvement of surgery residents in performing vascular surgical procedures, particularly CEA.

This study had limitations. It was limited to the experience of a single surgeon; however, this also ensured that all CEAs were performed in a consistent manner throughout the study period. While hospital environments were similar, some bias may have been introduced, as the residents, which were the focus of this investigation, were confounded by hospital location as there were no cases performed with and without resident participation in each of the participating hospitals.

\section{CONCLUSION}

In conclusion, general surgery residents did not have a significant impact on the risk of ischemic stroke and deaths from ischemic stroke in patients undergoing CEA.

\section{ACKNOWLEDGEMENT}

The author thanks Stephen D. Helmer, Ph.D., for providing statistical analyses for this article.

\section{REFERENCES}

${ }^{1}$ Bottsford JH, Blake R, Small T, Bottsford J. Carotid endarterectomy: The outcome is not adversely affected by surgical residents. J S C Med Assoc 1997; 93(7):243-247. PMID: 9239963.

${ }^{2}$ Graham AM, Salasidis GC, Ferneini AM. Carotid endarterectomy in a vascular fellowship training program: Good results with a consistent technique. Can J Surg 1995; 38(1):39-41. PMID: 7882207.

${ }^{3}$ Peters RA, Hanson TL, Fontenelle LJ. The influence of resident surgical training on outcome of carotid endarterectomy in a teaching hospital. Surg Gynecol Obstet 1988; 166(6):487-490. PMID: 3375960.

4 Krupski WC, Effeney DJ, Goldstone J, et al. Carotid endarterectomy in a metropolitan community: Comparison of results from three institutions. Surgery 1985; 98(3):492-499. PMID: 4035569.

${ }^{5}$ Hertzer NR, Avellone JC, Farrell CJ, et al. The risk of vascular surgery in a metropolitan community. With observations on surgeon experience and hospital size. J Vasc Surg 1984; 1(1):13-21. PMID: 6481861.

${ }^{6}$ Lutz H, Michael R, Gahl B, Savolainen H. Is carotid endarterectomy a trainee operation? World J Surg 2009; 33(2):242-245. PMID: 19034569.

7 Black SA, Harrison RH, Horrocks EJ, Pandey VA, Wolfe JH. Competence assessment of senior vascular trainees using a carotid endarterectomy bench model. Br J Surg 2007; 94(10):1226-1231. PMID: 17579347.

${ }_{8}$ Bradbury AW, Brittenden J, Murie JA, Jenkins AM, Ruckley CV. Supervised training in carotid endarterectomy is safe. Br J Surg 1997; 84(12):1708-1710. PMID: 9448621.

9 Naylor AR, Thompson MM, Varty K, Sayers RD, London NJ, Bell PR. Provision of training in carotid surgery does not compromise patient safety. Br J Surg 1998; 85(7):939-942. PMID: 9692568.

${ }^{10}$ Stone ME Jr, Kunjummen BJ, Moran JC, Wilkerson DK, Zatina MA. Supervised training of general surgery residents in carotid endarterectomy performed on awake patients under regional block is safe and desirable. Am Surg 2000; 66(8):781-786. PMID: 10966040.

11 Reeves JG, Kasirajan K, Veeraswamy RK, et al. Characterization of resident surgeon participation during carotid endarterectomy and impact on perioperative outcomes. J Vasc Surg 2012; 55(1):268-273. PMID: 22051871 .

${ }^{12}$ Grizzell BE, Ammar AD, Helmer SD. Carotid stenosis: Change of treatment plan based on repeat duplex ultrasonography. Am J Surg 2012; 203(2):121-126. PMID: 21784407.

${ }_{13}$ Ammar AD. Cost efficient carotid surgery: A comprehensive evaluation. J Vasc Surg 1996; 24(6):1050-1056. PMID: 8976360.
KANSAS JOURNAL of MEDIC INE

IMPACT OF SURGERY RESIDENTS ON CEA

\section{OUTCOMES}

continued.

${ }^{14}$ Ammar CP, Helmer SD, Ammar AD. Carotid duplex ultrasonography: Additional imaging is rarely necessary for appropriate treatment planning for carotid artery disease. Am Surg 2017; 83(4):377-380. PMID: 28424133.

${ }_{15}$ Ammar AD, Pauls DG. Correlation of carotid artery stump pressure with a palpable carotid artery pulse. J Cardiovasc Surg (Torino) 1992; 33(1):5961. PMID: 1544998.

${ }_{16}$ Ammar AD. Is intensive care necessary following carotid endarterectomy? Kans Med 1995; 96(3):125-126. PMID: 8583737.

Keywords: internship and residency, operative surgical procedures, carotid endarterectomy, stroke 